\title{
Recorregut de recerca geològica i mineralògica per les comarques de la Plana Alta i de l'Alt Millars: des de Ribesalbes a Fanzara, Toga, Cirat i a Montanejos
}

Josep Maria Mata-Perelló

Joaquim Sanz Balagué

Jaume Vilaltella Farràs

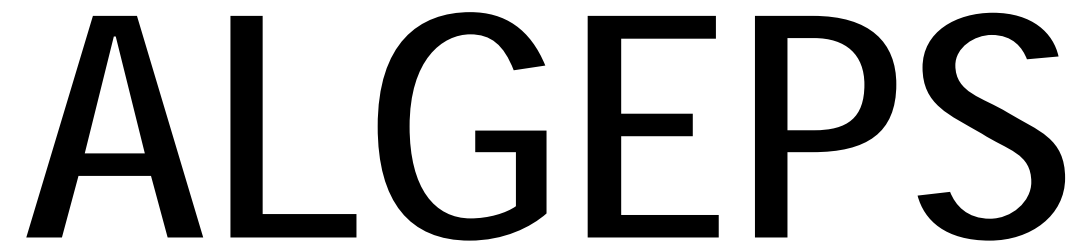

\section{REVISTA DE GEOLOGIA}

\section{n. 1}

GENER 2015 


\title{
RECORREGUT DE RECERCA GEOLÒGICA I MINERALÒGICA PER LES COMARQUES DE LA PLANA ALTA I DE L'ALT MILLARS: DES DE RIBESALBES A FANZARA, TOGA, CIRAT I A MONTANEJOS
}

\author{
Josep Maria Mata-Perelló \\ Museu de geologia Valentí Masachs, Escola Politècnica Superior d'Enginyeria de Manresa \\ (EPSEM), Universitat Politècnica de Catalunya · BarcelonaTech (UPC), 08272 Manresa, Spain
}

\section{Joaquim Sanz Balagué}

Departament d'Enginyeria Minera i Recursos Naturals (EMRN), Escola Politècnica Superior d'Enginyeria de Manresa (EPSEM), Universitat Politècnica de Catalunya - BarcelonaTech (UPC), 08272 Manresa, Spain

Jaume Vilaltella Farràs

Paraules clau: Patrimoni geològic i miner; Sistema ibèric; País Valencià

\section{Resum}

Itinerari realitzat el dia 1 de maig del 2014. Aquest itinerari geològic i mineralògic, discorrerà íntegrament dintre del Sistema Ibèric. Tot i trobar-se lluny de la denominada Zona d'Enllaç, es troba sovint afectada per fractures de direcció catalana.

De fet, la totalitat del recorregut es situarà dintre dels denominats relleus triàsics de Sagunt (Oriol RIBA et altri, 1976). Així, en la major part dels trajectes anirem trobant afloraments dels diferents materials mesozoics. Aquests es distribueixen segons els indrets entre el Triàsic, el Juràssic i el Cretàcic.

Els materials triàsics que trobarem al llarg del recorregut, pertanyen majoritàriament al Keuper, als trams guixosos i argilosos del Triàsic Superior. Per d'altra banda, els materials juràssics que trobem en aquesta zona són majoritàriament calcaris i descansen sobre la discontinuïtat generada al fina del Triàsic. El mateix es pot dir dels afloraments cretàcics que anirem trobant al llarg del recorregut.

Allí on trobem materials de Juràssic $i$ del Cretaci són freqüents els fenòmens d'erosió per carstificació del substrat, això condiciona la formació de congostos i relleus molt escarpats deguts a l'enfonsament d'antigues cavitats càrstiques. Per d'altra banda, al llarg del recorregut $d$ 'aquest itinerari ens centrarem en el reconeixement de diferents mineralitzacions, que anirem trobant a diferents indrets del recorregut.

Finalment, cal dir que aquest itinerari transitarà íntegrament quasi per una sola comarca, concretament per la de l'Alt Millars. Tot $i$ això, els primers trams del recorregut es realitzaran per la comarca de la Plana Alta, entre Ribesalbes, Onda i les immediacions de Fanzara. 


\section{Objectius fonamentals}

Dintre d'aquest itinerari, ens fixarem els següents objectius, d'acord amb el sentit de la marxa:

1.- Estudi i observació dels materials mesozoics, que constitueixen el Sistema Ibèric, per on discorrerà la totalitat del recorregut de l'itinerari, entre les poblacions de Ribesalbes i Onda (situades a la Plana Alta) i la localitat de Montanejos (Alt Millars). Aquests materials es distribuiran entre el Triàsic (Keuper), Juràssic i Cretàcic.

2.- Observació de les estructures del Sistema Ibèric i de les interferències amb les estructures catalanes.

3.- Estudi de diverses mineralitzacions situades entre els materials triàsics del Sistema Ibèric. Entre aquestes, farem esment de les següents, d'acord amb el sentit de la marxa del recorregut:

3A) Mineralitzacions digenètiques, de diverses connotacions, situades entre els materials triàsics del Keuper, que es troben a diversos indrets del recorregut.

3B) Mineralitzacions evaporítiques, situades com les anteriors a diversos llocs d'aquest recorregut.

4.- Observació d'algunes explotacions mineres (subterrànies o a "cel obert"), antigues o actuals, com les explotacions de les calcàries triàsiques de les immediacions de Toga (a la comarca de l'Alt Millars).

5.- Observació de l'impacte produït per les explotacions anteriors sobre el medi natural, i si s'escau de les restauracions dutes a terme per reduir aquest impacte.

6.- Observació dels diferents indrets relacionats amb el nostre Patrimoni Geològic i Miner que anem trobant al llarg del recorregut de l'itinerari, i en especial dels que puguin ésser catalogats com a LIG (Llocs d’Interès Geològic) o com a LIPM (Llocs d'Interès del Patrimoni Miner).

\section{Antecedents}

No existeix cap antecedent bibliogràfic, relatius a trams del recorregut d'aquest itinerari. Tot i així hi ha alguns antecedents parcial a uns treballs nostres, de fa uns anys Es tracta de MATAPERELLÓ i VILALTELLA (2005a i 2005b). Tret d'aquests treballs, no en coneixem cap més.

Pel que fa a l'estudi de les mineralitzacions situades al llarg del recorregut, farem un especial esment del treball de MATA-PERELLÓ (1984), relatiu a les mineralitzacions que s'estenen per les comarques per les quals discorre el recorregut de l’itinerari.

Pel que fa a l'estructura geològica dels indrets pels quals discorrerà el recorregut de l'itinerari, farem esment de dos treballs generals, relatius al conjunt dels Països Catalans: GUIMERÀ et altri (1992), i RIBA et altri (1976). Igualment, cal fer esment dels diferents fulls del Mapa Geológico de España corresponents a la zona per la qual discorrerà el recorregut de l'itinerari.

Tots aquests treballs esmentats, i d'altres, figuraran per ordre alfabètic a l'apartat dedicat a la bibliografia. 


\section{Recorregut de l'itinerari}

El recorregut d'aquest itinerari comença a la comarca de la Plana Alta, per les immediacions de la població de Ribesalbes, des d'on s'anirà immediatament cap a la capital comarcal, la població d'Onda, seguint la carretera $C V-191$. Ben seguit es continuarà per la carretera que es dirigeix cap a Fanzara, seguint la carretera autonòmica valenciana $C$ - 20. Posteriorment, seguint l'esmentada carretera, ens caldrà anar cap a les immediacions de la població de Toga. En aquesta primera part del recorregut es faran diverses aturades.

Després, el recorregut es dirigirà cap a les poblacions de Torrechiva, Cirat, Arañuel i Montanejos, per on finalitzarà el recorregut. En aquesta segona part del recorregut, es realitzaran diverses aturades

\section{Advertiments previs}

Com en altres recorreguts de recerca geològica i mineralògica ..., si es disposa del temps suficient, poden efectuar-se passant per totes les parades i filloles. En cas contrari, recomanem prescindir de les anomenades parades - condicionals.

També cal tenir en conte que una part del recorregut final de l'itinerari, es realitzarà per camins de terra, per la qual cosa caldrà prendre les degudes precaucions. Així, d'aquesta manera es circularà pels diferents camins d'accés a les mines.

Cal tenir, com sempre, una cura molt especial de respecte a la natura, al llarg de tot el recorregut de l'itinerari, i també fora d'ell.

\section{Descripció de l'ítinerari}

Com en altres itineraris, a continuació veurem una sèrie de "parades o estacions". En cada una d'elles es farà un breu comentari, ja sigui de caràcter geològic, geomorfològic o mineralògic, segons s'escaigui.

Per d'altra banda, darrera del nom de l'indret (o de la parada), situarem entre parèntesi el número del Mapa Topogràfic, a escala 1:50.000, on es troba l'indret de l'aturada. En aquesta ocasió, utilitzarem diferents fulls de l'esmentat mapa topogràfic; concretament, els següents: 614 (o de Manzanera). 615 (anomenat també com a full d'Alcora) i el 640 (conegut con a full d'Onda i antigament com a full de Sogorb). Cal dir que tots aquest full ha estat publicats pel Instituto Geográfico y Catastral de España.

Així doncs, la relació general de les aturades que constitueixen aquest itinerari, d'acord amb el sentit de la marxa, és el següent:

\subsection{Parada 1. Sortida d'Onda cap a Montanejos, (terme municipal d'Onda, comarca de la Plana Alta). (Full 640).}

Tot i que el recorregut I'haurem començat a Ribesalbes, ens caldrà fer un recorregut previ, per tal d'anar cap a la localitat d'Onda, situada dintre de la comarca de la Plana Alta, de la qual n'és la capital, ubicada dintre de la Regió de Castelló. Per anar-hi, utilitzarem la carretera autonòmica CV - 191. Després, des d'Onda, ens caldrà sortir per la carretera que condueix 
cap a Montanejos, concretament la CV - 20. A la sortida d'Onda, farem una primera aturada, si $\mathrm{s}^{\prime}$ escau, a uns $9 \mathrm{Km}$ des de l'inici del recorregut.

Aquest indret es troba situat al bell mig de la Depressió de la Plana, a tocar de les estructures de la Serralada Ibèrica, per on discorrerà la totalitat de la resta del recorregut del present itinerari. Cal dir que bona part del recorregut des de I'inici d'aquest tram, I'hem fet dintre de la depressió abans esmentada.

En aquest indret es pot gaudir de la observació de la Plana. Aquesta es troba reblada de materials cenozoics, en bona part recobertes per terrenys quaternaris, sovint de derrubis de pendent, que són els que apareixen a l'indret on ara som.

\subsection{Parada 2 - condicional. Gravera de la carretera a Montanejos (terme municipal de Fanzara, comarca de l’Alt Millars I Alto Mijares). (Full 615).}

Després de fer la parada anterior, cal seguir per la carretera autonòmica que es dirigeix cap a Montanejos; la CV-20. Però a uns $5 \mathrm{Km}$ d'Onda i a uns $3 \mathrm{Km}$ de la cruïlla amb la carretera procedent de Ribesalbes, cal fer una nova aturada, prop d'una explotació actual d'àrids per a la construcció.

En aquest recorregut, hem continuat trobant els materials cenozoics que hem esmentat a la parada anterior; tot i que ens trobem molt a prop dels afloraments mesozoics de la Serralada Ibèrica.

En aquest indret, hi ha una explotació d'àrids per a la construcció. Els materials explotats són els terrenys quaternaris que hem esmentat anteriorment. Cal dir, al respecte de la pedrera, que per entrar-hi, cal demanar la corresponent autorització.

\subsection{Parada 3. Carretera a Montanejos, CV-194, immediacions del km 8, (terme municipal de Fanzara, comarca de I’Alt Millars I Alto Mijares). (Full 615).}

Després de fer l'aturada anterior, cal seguir per la carretera que es dirigeix cap a Montanejos, la CV-20. Tot i que després seguirem pel seu tram antic (I'actual carretera CV-194). Així, en arribar a les immediacions de l'antic $\mathrm{Km} \mathrm{8}$, farem una nova aturada, a uns $5 \mathrm{Km}$ de l'anterior.

En aquest recorregut, hem anat trobant els materials mesozoics que formen part de la Serralada Ibèrica. Aquests materials són en bona part del Triàsic, fonamentalment del Keuper, tot i que també hem trobat afloraments del Juràssic i del Cretàcic.

En aquest indret ens trobem davant d'un aflorament dels materials triàsics del Keuper. Entre aquests materials, a més a més del GUIX, molt abundant, també trobem diversos minerals digenètics com els següents: dolomita (negra, en la varietat que es coneix com a teruelita), pirita (en piritoedres) i quars (en la varietat de jacints de compostela).

\subsection{Parada 4. Cruïlla de carreteres, CV-194, (terme municipal d'Argelita, comarca de I’Alt Millars I Alto Mijares). (Full 615).}

Després de fer la parada anterior, cal continuar per la carretera que es dirigeix cap a Fanzara. Després ens caldrà seguir cap a Vallat i cap a Toga. En arribar a la cruïlla d'aquesta carretera amb la que uneix Toga amb Argelita, cal fer una nova aturada, a uns $9 \mathrm{Km}$ de la parada anterior.

En aquest recorregut, hem anat trobant afloraments dels materials mesozoics del Triàsic (fonamentalment del Keuper i del Muschelkalk), com als trajectes cap a les dues parades 
anteriors. Aquests materials formen part dels afloraments del Sistema Ibèric, per on s'està desenvolupant tot aquest recorregut.

En aquest indret hi ha un interessant aflorament dels materials triàsics del Keuper, els quals es troben constituïts per trams de guixos i d'argiles. Els primers son de tonalitats blanquinoses, grises i rogenques.

El mateix que les argiles, que són clarament versicolors. Per d'altra banda, amb els materials anteriors, també és fan clarament paleses les carnioles. Aquestes darreres són normalment de tonalitats ocres

En aquest indret apareixen diverses cristal-litzacions. Així es fan força palesos els cristallets de QUARS (incolors i rojos, el típics jacints de compostela), que es troben entre els guixos rogencs i entre els blanc. També es fan palesos els cristalls de dolomita (de tonalitats negres, formant les denominades teruelites), que es troben entre els nivells de guixos i argiles grisenques. Tanmateix, també es troben petits cristallets de pirita (en piritoedres, molt rovellats, amb pàtina negra). Finalment, cal parlar de la presència del propi guix i de la goethita (en concrecions d'aspecte limonític).

\subsection{Parada 5 - condicional. Pedrera del km 9 de la carretera CV - 194, de Toga a Argelita, (terme municipal d'Argelita, comarca de I’Alt Millars I Alto Mijares). (Full 615).}

Després de fer la parada anterior, cal continuar per la carretera que es dirigeix cap al poble d'Argelita amb Toga. En arribar a les immediacions del Km 0'9, caldrà fer una nova aturada. Per fer aquesta aturada, ens caldrà fer una fillola.

En aquest recorregut, hem anat trobant afloraments dels materials mesozoics del Triàsic (fonamentalment del Keuper i del Muschelkalk). Aquests materials formen part dels afloraments del Sistema Ibèric, per on s'està desenvolupant tot aquest recorregut.

Com al cas anterior, en aquest lloc, també hi ha un aflorament de les calcàries triàsiques del Muschelkalk. Aquestes calcàries han estat explotades en diferents èpoques, per tal d'ésser emprades com a matèria prima per a l'obtenció d'àrids per a la construcció.

Actualment, aquesta pedrera, situada per sobre de la carretera, es troba aturada. A diferencia de la pedrera anterior, en cara es conserven les instal-lacions de la pedrera. (fotografia 1).

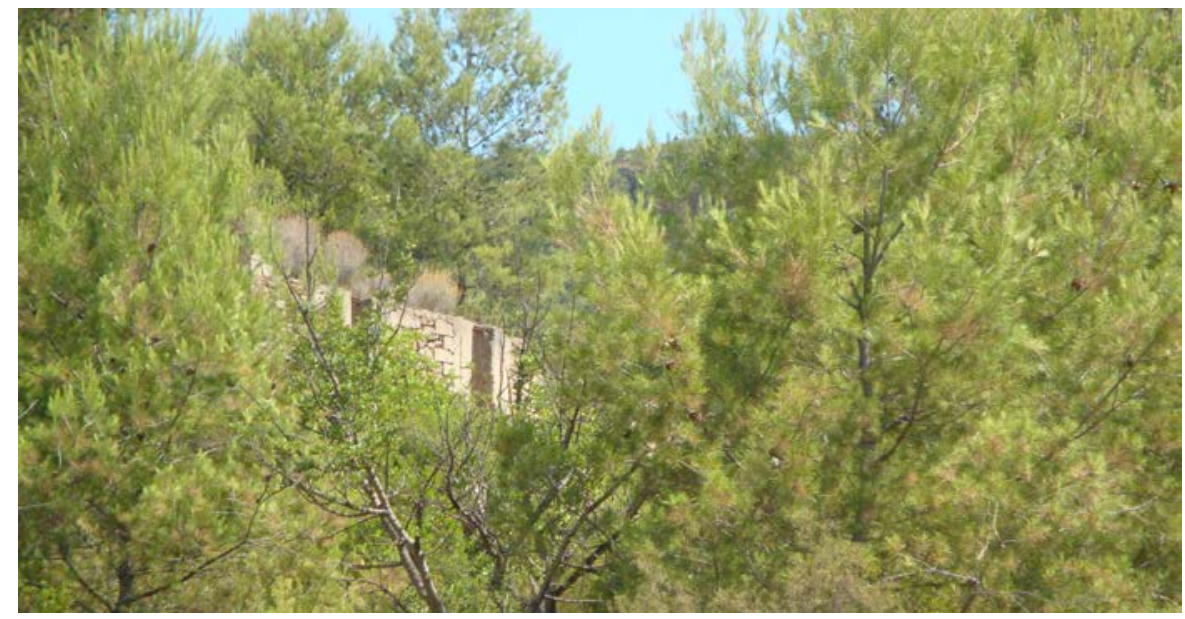

FOTOGRAFIA 1. Restes de les instal-lacions de la pedrera d'Argelita 


\subsection{Parada 6. Meandre del Millars a Cirat, carretera CV-20, (terme municipal de Cirat, comarca de I'Alt Millars I Alto Mijares). (Full 615).}

Després de fer la parada anterior, cal retrocedir fins a la cruilla on hem fet la PARADA 4, per tal de continuar per la carretera CV - 198. Per aquesta, arribarem a la població de Toga, després, seguint per aquesta carretera arribarem de nou a la CV - 20, per la qual continuarem remuntant el riu Millars / Mijares. En fer-ho, passarem per les poblacions de Torrechiva i el Tormo. Finalment arribarem a Cirat, per on farem una nova aturada, a uns $15 \mathrm{Km}$ de la parada anteriorment realitzada.

En aquest recorregut, hem anat trobant afloraments dels materials eminentment carbonatats (del Juràssic i del Cretàcic). Ocasionalment, haurem trobat afloraments dels materials del Triàsic Superior (del Keuper), amb trams de guixos i d'argiles. Tots aquests materials es situen dintre del Sistema Ibèric.

Des d'aquest indret, es pot gaudir d'una bona observació del riu Millars / Mijares, que aquí descriu un meandre ben vistós.

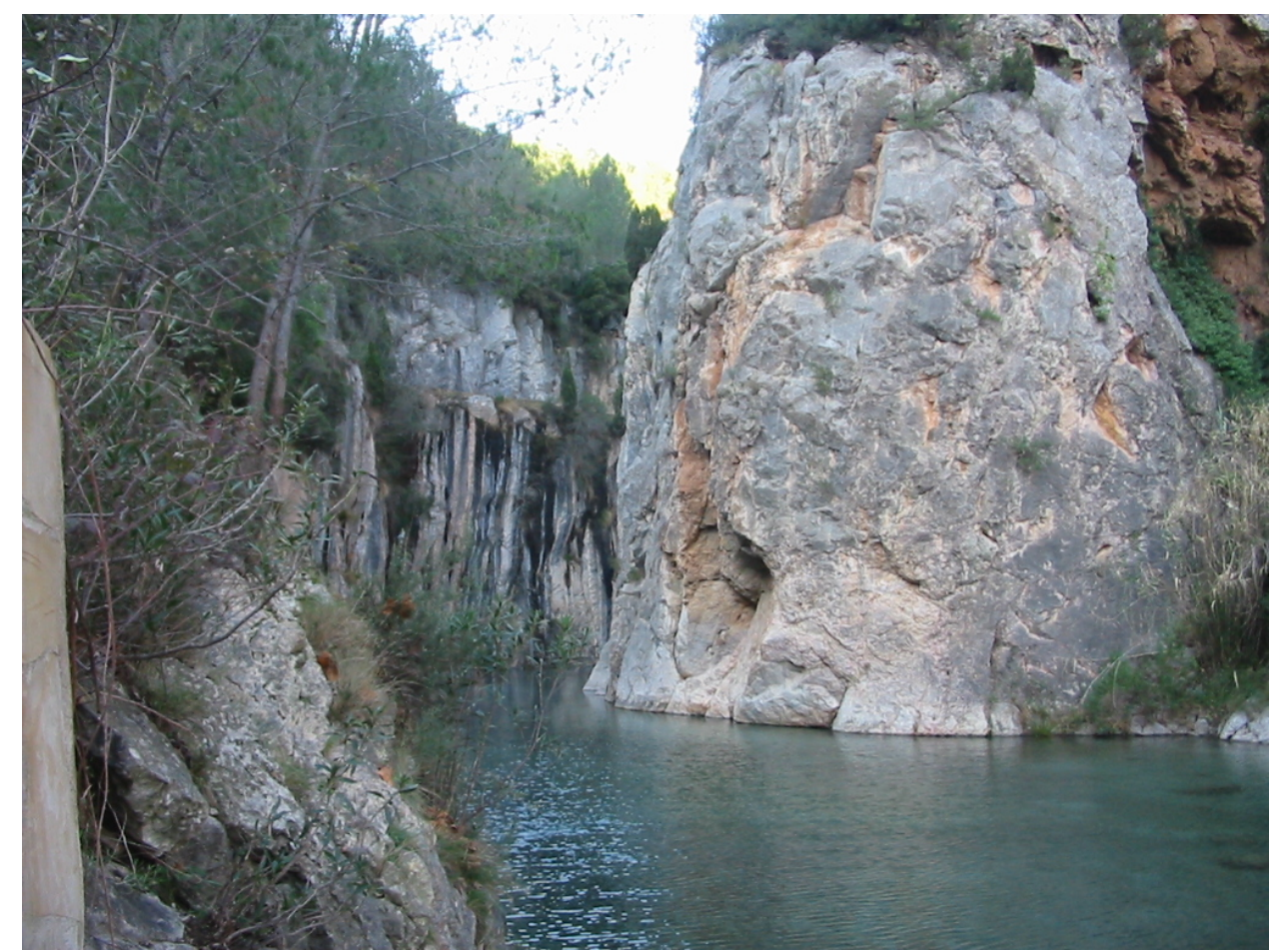

FOTOGRAFIA 2. El riu Millars, entre afloraments carbonatats cretàcics. Fuente de los Baños

\subsection{Parada 7. Fuente de los Baños, carretera de Montanejos a la Pobla d'Arenós (terme municipal de Montanejos, comarca de l'Alt Millars I Alto Mijares). (Full 614).}

Després de fer la parada anterior, cal continuar per la carretera que es dirigeix cap a Montanejos, la CV - 20. Abans, però, es passarà per les localitats d'Arañuel i de l'Alqueria. Finalment, després de sobrepassar lleugerament la població de Montanejos, continuant per 
I'esmentada carretera, ens caldrà deixar-la per tal d'apropar-nos al riu Millars / Mijares, on hi ha la Fuente de los Baños. Aquí farem la darrera aturada d'aquest itinerari, a uns $9 \mathrm{~km}$ de la darrera aturada.

En aquest recorregut, hem continuat trobant afloraments dels materials mesozoics de la Serralada Ibèrica, per on estem ara situats. Així, fonamentalment, haurem trobat afloraments dels materials carbonatats del Juràssic i del Cretàcic.

En aquest indret hi una important surgència d'aigües lleugerament termals (hipotermals) que surten a uns $25^{\mathrm{a}} \mathrm{C}$. Es tracta d'un important naixement d'aigua, d'uns 6000 litres / minut. Just a la sortida hi ha una important formació travertínica. Aquest indret constitueix un important LIG, dintre del nostre Patrimoni Geològic, tot i trobar-se molt antropitzat. (fotografies 2 i 3).

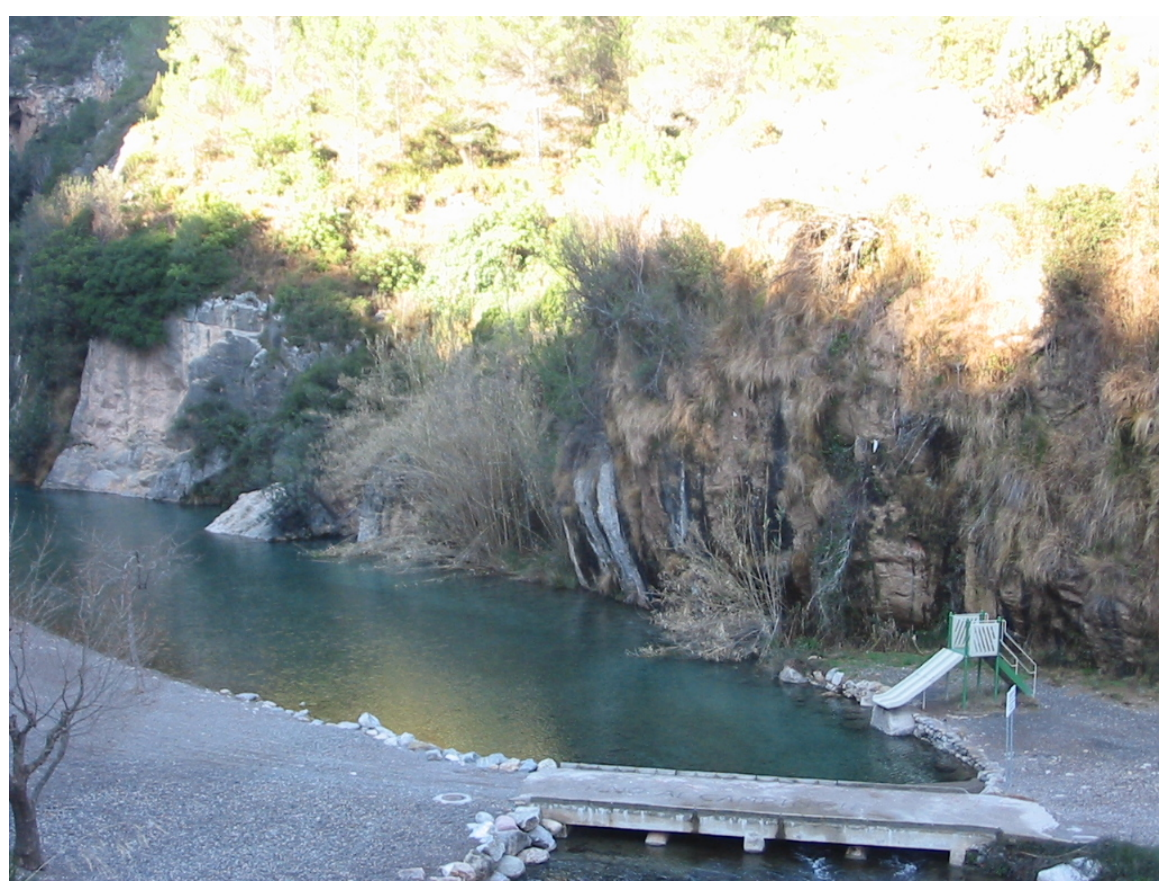

FOTOGRAFIA 3. Un aspecte del paratge de la Fuente de los Baños

En aquest indret finalitza l'itinerari

\section{Bibliografia}

GUIMERÀ, J. et altri /1992).- Geologia (II), Història Natural dels Països Catalans, Vol.2, 547 pag. Enciclopèdia Catalana, S,A,, Barcelona

LOPEZ, J. i ARCHE, A. (1986).- Estratigrafia del Permico y Triàsico, en facies Buntsandsteim y Muschelkalk, en el sector Sudeste de la rama castellana de la Cordillera Ibérica (Provincias de Cuenca y de Valéncia). Estudios Geológicos, nº. 42, pp. 123-143. Madrid

MATA-PERELLÓ, J.M. (1984).- Els Minerals del País Valencià, Col-lecció Informe, nº 6, 546 pàgines. Manresa 
MATA-PERELLÓ, J.M. i SANZ BALAGUER, J. (1988).- Guia de determinació de Minerals, adaptada als Països Catalans. Parcir, Edicions Selectes, 207 pàgines. Manresa.

MATA-PERELLÓ, J.M, i VILALTELLA FARRÀS, J. (2005a).- Recorregut de recerca geològica i minera per les comarques de l'Alcalatén i de I'Alt Millars: des de Llucena a Argelita. Inèdit, 10 pag. Manresa

MATA-PERELLÓ, J.M, i VILALTELLA FARRÀS, J. (2005b).- Recorregut de recerca geològica i mineralògica per les comarques de la Plana Alta i per I'Alt Millars: des d'Onda a Toga i a Argelita. Inèdit. 8 pàgines. Manresa

RIBA, O. et altri (1976).- Geografia Física dels Països Catalans. Edit. Ketres, 254 pàgines. Barcelona 